\title{
Avaliação dos fatores que influenciam os autos de infração por poluição sonora
}

\section{Evaluation of factors that influence the infraction notice for noise pollution}

\author{
Francisco Ivander Amado Borges Alves ${ }^{1 *}$; Jackeline Lucas Souza ${ }^{2}$; Lys Bessa Peixoto \\ Correio $^{2}$
}

\author{
${ }^{1 *}$ Francisco Ivander Amado Borges Alves* (autor correspondente) \\ Concentrix, Fortaleza - Ceará, Brasil, 60020-180, ivandborges@ gmail.com; \\ https://orcid.org/0000-0001-7633-2966
}

\begin{abstract}
${ }^{2}$ Universidade Federal do Ceará, Fortaleza - Ceará, Brasil, 60020-180, jackeline.souza@hotmail.com; https://orcid.org/0000-0002-0012-6717;

lysbessap@gmail.com; https://orcid.org/0000-0003-2234-7681
\end{abstract}

\section{Resumo}

O meio ambiente é imprescindível a todas as esferas da sociedade. Mais do que nunca se nota a importância de zelar pelos bens naturais e pelo meio ambiente ecologicamente equilibrado, uma vez que estes não pertencem a ninguém de forma privativa e sua utilização deve ser consciente, sobretudo para que as próximas gerações usufruam desse ambiente e que os impactos ambientais sejam minimizados. Esta pesquisa coletou-se 555 autos de infrações ambientais da categoria poluição sonora, referentes ao ano de 2017 , disponibilizados pela SEUMA - Secretaria de Urbanismo e Meio Ambiente, buscando analisar a capacidade econômica do infrator, a gravidade do dano e a reincidência da infração como características influenciadoras nos valores das multas, segundo o Decreto $n^{\circ} 6.514 / 2008$. No modelo de equação aplicado verificou-se que duas variáveis influenciaram positivamente o valor das multas (capacidade econômica do infrator e reincidência da infração); por sua vez, a variável potencial poluidor não influenciou o valor da multa por infração ambiental, estando parcialmente em desacordo com a legislação aplicável.

Palavras chave: poluição sonora, fatores determinantes, infração ambiental, multa ambiental, lei ambiental. 


\begin{abstract}
The environment is essential to all spheres of society. More than ever, the importance of caring for natural goods and for an ecologically balanced environment is noted, since they do not belong to anyone privately and their use must be conscious, especially so that the next generations enjoy this environment and that environmental impacts are minimized. This research collected 555 notices of environmental violations in the noise pollution category, for the year 2017, made available by the SEUMA - Secretariat of Urbanism and Environment, seeking to analyze the economic capacity of the offender, the severity of the damage and the recurrence of the infraction. as influencing characteristics in the values of fines, according to Decree No. 6,514 / 2008. In the applied equation model, it was found that two variables positively influenced the value of fines (economic capacity of the offender and recurrence of the infraction), while the potential polluting variable did not influence the value of the fine for environmental infraction, being partially at odds with the applicable legislation.
\end{abstract}

Keywords: noise pollution, determining factors, environmental infraction, environmental fine, environmental law.

\title{
1. Introdução
}

Diante da exploração excessiva dos bens ambientais, sejam estes renováveis ou não, percebe-se um desequilíbrio na harmonia dos elementos que constituem o meio ambiente. Os fatores que causam esse desequilíbrio precisam ser conhecidos e, principalmente, mensurados, para que se possa punir com equidade aqueles que causaram tal dano.

A Lei $\mathrm{n}^{\circ}$ 9.605, de 12 de fevereiro 1998, também chamada de Lei de Crimes Ambientais, dispõe sobre as sanções penais e administrativas, consequências de condutas e atividades que sejam danosas ao meio ambiente. Essa lei começa a inserir o entendimento do que, verdadeiramente, é crime ambiental e quais são os resultados para o praticante desse crime.

Outrossim, o art. $4^{\circ}$ do Decreto $n^{\circ} 6.514$, de 22 de julho de 2008, estabelece como o processo administrativo federal deve apurar as infrações ambientais e dispõe que no processo de lavratura do auto de infração, devem ser indicados os elementos basilares, sendo estes: a gravidade do fato; os antecedentes do infrator; e a situação econômica do infrator. Segundo o Decreto, esses elementos são basilares ao cálculo da multa por infração ambiental.

Diante do exposto, a poluição é uma forma de degradação do meio ambiente recorrente atualmente, sendo classificadas na legislação municipal de Fortaleza/CE em sete categorias: visual e luminosa, sonora, atmosférica, licenciamento, efluentes, construção e resíduos sólidos. 
Nesse contexto, o estudo se propõe a avaliar os fatores determinantes das infrações ambientais por poluição sonora, ocorridas no município de Fortaleza/CE, aplicadas de acordo com os dispositivos do art. $4^{\circ}$ do Decreto ${ }^{\circ}$ 6.514, de 22 de julho de 2008. A formulação da questãoproblema enfatiza responder o seguinte problema: Quais fatores influenciam os autos de infração por poluição sonora? Para responder a esse problema, foi traçado como objetivo geral: avaliar os fatores que influenciam os autos de infração por poluição sonora.

Logo, percebe-se a importância de verificar se a lei está sendo cumprida, parcialmente, para que não haja poluição sonora do ambiente. Este trabalho promove a percepção por parte dos órgãos públicos quanto à aplicação da lei e proporciona a concepção de políticas públicas ambientais que devem ser tomadas para evitar a exploração do meio ambiente. Outrossim, para pesquisadores, o trabalho deve gerar conhecimento específico sobre infrações ambientais por poluição sonora, colaborando para o desenvolvimento de políticas públicas ambientais.

Ademais, o estudo surge pela necessidade de compreender os fenômenos econômicos que formam o valor da multa aplicada às infrações por poluição sonora do município de Fortaleza/CE, além de possuir carácter prático e transdisciplinar, uma vez que o impacto ambiental sonoro é explorado neste estudo pela valoração econômica do dano, marcado por subjetividade e discricionariedade.

\section{Material e Métodos}

A metodologia utilizada na pesquisa quanto aos objetivos foi descritiva, utilizando uma abordagem quali-quantitativa, visto que foi tanto foi realizada pesquisa documental e análise de conteúdo dos autos como aplicados instrumentos estatísticos. Os dados foram coletados no sistema DATAGED - banco de dados que armazena todo o conteúdo informacional de natureza ambiental, desde o termo de fiscalização até o pagamento e/ou arquivamento dos autos de infração gerados pela SEUMA -. A análise foi realizada por meio da estatística descritiva e da regressão linear múltipla.

Inicialmente, foi repassado aos pesquisadores uma planilha do Microsoft ${ }^{\circledR}$ Excel 2010, a qual continha o número dos processos ambientais do ano de 2017 no município de Fortaleza. De posse desses dados, acessou-se o sítio do DATAGED, entre dia 13 de março e 31 de julho 
de 2017, para consultar demais informações contidas nos autos como bairro da infração, tipo de infrator (Pessoa Física ou Jurídica), categoria da infração, valor da multa atribuída, valor da multa paga, se a infração era potencial poluidor e se o infrator era reincidente.

Todos os dados coletados no DATAGED foram organizados na mesma planilha enviada com os números dos processos, com cada auto disposto numa linha e as outras informações nas colunas. Foram levantados 1.633 autos de infração, do ano de 2017, por danos causados ao meio ambiente em Fortaleza/CE, na SEUMA. Em seguida, procedida análise de conteúdo dos dados de acordo com as variáveis independentes utilizadas: a reincidência, a gravidade do dano e a capacidade econômica do infrator.

Os autos foram segregados em sete categorias: licenciamento ambiental, poluição sonora, poluição atmosférica, poluição visual, resíduos sólidos, efluentes e construção, onde na categoria poluição sonora foram identificados 555 autos (34\% da população).

A Lei $n^{\circ} 9.605 / 98$ e o Decreto $n^{\circ} 6.514 / 08$ estabelecem que os critérios a serem utilizados na definição do valor das multas por infração sonora devem ser: a gravidade do dano, a reincidência do infrator e sua situação econômica. Este estudo aplica modelo de regressão linear múltipla (Equação 1) para identificar se as variáveis, presentes na legislação federal, estão sendo observadas pelo fiscal quando este atribui valor à multa por poluição sonora.

$$
\text { Multa }=f\left(\beta_{1} G D, \beta_{2} C E, \beta_{3} R E I N\right)
$$

Onde: Multa - Valor em reais (R\$) aplicado ao infrator ter causado em poluição sonora

GD - Gravidade do dano

CE - Capacidade econômica

REIN - Reincidência

Para análise da regressão linear múltipla das três variáveis independentes - gravidade do dano (GD), capacidade econômica (CE) e reincidência da infração (REIN) - foram levantados estes dados nos autos de infração da SEUMA.

A variável GD refere-se a análise, feita pelo agente fiscalizador, das consequências daquela infração à saúde pública e ao meio ambiente, indicando se possui ou não potencial poluidor. Essa informação foi coletada nos autos de infração do DATAGED na seção "Observações” e 
a operacionalização dela é do tipo binária, ou seja, conferiu-se nos autos se constava a informação de "potencial poluidor", atribuindo-se valor 1 à variável para este caso e 0 , caso contrário.

Quanto a CE, primeiramente, segregou-se o perfil dos infratores, em Pessoa Física (PF) e Pessoa Jurídica (PJ). Para o primeiro, foi estabelecida a renda per capita do bairro onde ocorreu a infração para designar sua capacidade econômica, conforme informações do Instituto Brasileiro de Geografia e Estatística (IBGE, 2017). Já para o segundo, o critério adotado para modelar esta variável foi baseado no faturamento bruto aceito para os tipos de empresas de acordo com a legislação brasileira.

Mesmo a legislação federal indicando três parâmetros que devem ser considerados na definição da multa por poluição sonora, este valor não poderia ser ilimitado. A este respeito, foi observado que coube à legislação municipal estipular tais limites (valores mínimo e máximo) para as multas aplicadas, vigente nas Leis Municipais de Fortaleza ${ }^{\circ} 10.644$, de 22 de novembro de 2017, $\mathrm{n}^{\circ}$ 8.097, de 02 de dezembro de 1997 e $\mathrm{n}^{\circ} 4.822$, de 27 de dezembro de 1976. Abaixo (Quadro 1) relacionam-se as medidas administrativas, o valor das multas de acordo com a infração por poluição sonora e o número de autuações.

Quadro 1. Infrações, medidas administrativas e multas

\begin{tabular}{|c|c|}
\hline \multicolumn{2}{|r|}{ Infração: estabelecimentos sem autorização especial de utilização sonora } \\
\hline $1^{0}$ Autuação & $\begin{array}{l}\text { Advertência para fazer cessar a irregularidade e multa entre } \mathrm{R} \$ 500,00 \text { e } \\
\mathrm{R} \$ 5.000,00\end{array}$ \\
\hline $2^{\circ}$ Autuação & $\begin{array}{l}\text { Suspensão das atividades, apreensão dos equipamentos e multa entre } \\
\mathrm{R} \$ 1.000,00 \text { e } \mathrm{R} \$ 10.000,00\end{array}$ \\
\hline $3^{\circ}$ Autuação & $\begin{array}{l}\text { Cassação do Alvará de Funcionamento e multa entre } \mathrm{R} \$ 2.000,00 \text { e } \\
\mathrm{R} \$ 20.000,00\end{array}$ \\
\hline \multicolumn{2}{|r|}{ Infração: estabelecimentos com nível acústico acima do permitido } \\
\hline $1^{0}$ Autuação & $\begin{array}{l}\text { Advertência para fazer cessar a irregularidade e multa }(\mathrm{R} \$ 500,00 \text { a } \\
\mathrm{R} \$ 5.000,00)\end{array}$ \\
\hline $2^{\circ}$ Autuação & $\begin{array}{l}\text { Suspensão das atividades, apreensão dos equipamentos e multa entre } \\
\mathrm{R} \$ 1.000,00 \text { e } \mathrm{R} \$ 10.000,00\end{array}$ \\
\hline $3^{\circ}$ Autuação & $\begin{array}{l}\text { Cassação do Alvará de Funcionamento e multa entre } \mathrm{R} \$ 2.000,00 \text { e } \\
\mathrm{R} \$ 20.000,00\end{array}$ \\
\hline
\end{tabular}

Fonte: Adaptado da Lei no 8.097/97. 
A variável REIN foi designada para verificar se havia reincidência na autuação, considerando somente o infrator que cometeu a mesma infração, não interessando, portanto, se houve infração por outra categoria. $\mathrm{O}$ agente, no ato da fiscalização, indica se infrator é reincidente para aquele tipo de infração, utilizando a seção "Observações” para descrever o fato. No presente trabalho, foi aplicado 1 para indicar que houve reincidência e 0 quando não. Estas informações foram retiradas do auto de infração, pois nele o órgão fiscalizador descreve se o dano é potencialmente poluidor ou não, se o infrator possui antecedentes para o mesmo tipo de categoria e a perfil do infrator.

Após organização dos dados, foram traçadas as médias e os somatórios de cada variável, para aplicar regressão linear múltipla (Equação 1) procedendo, a partir dos dados exportados para programa estatístico STATA 12, na regressão o teste T a um nível significância de 1\%, se as variáveis influenciam o valor da multa da categoria de poluição sonora.

\section{Resultados}

Inicialmente, os autos foram organizados conforme as categorias apresentadas na seção anterior, de forma que, para a amostra analisada, os autos de infração por poluição sonora representaram o segundo lugar do total de autuações, com 555 observações (Gráfico 1). As principais autuações no município de Fortaleza foram dentro da categoria de licenciamento ambiental, com 592 autos de infração. Por sua vez, as categorias efluentes, poluição visual e construção tiveram 228, 175 e 37 observações, respectivamente, e nos últimos lugares ficaram a poluição atmosférica com 21 e resíduos sólidos com 8 . 
Gráfico 1. Quantidade de infrações das categorias

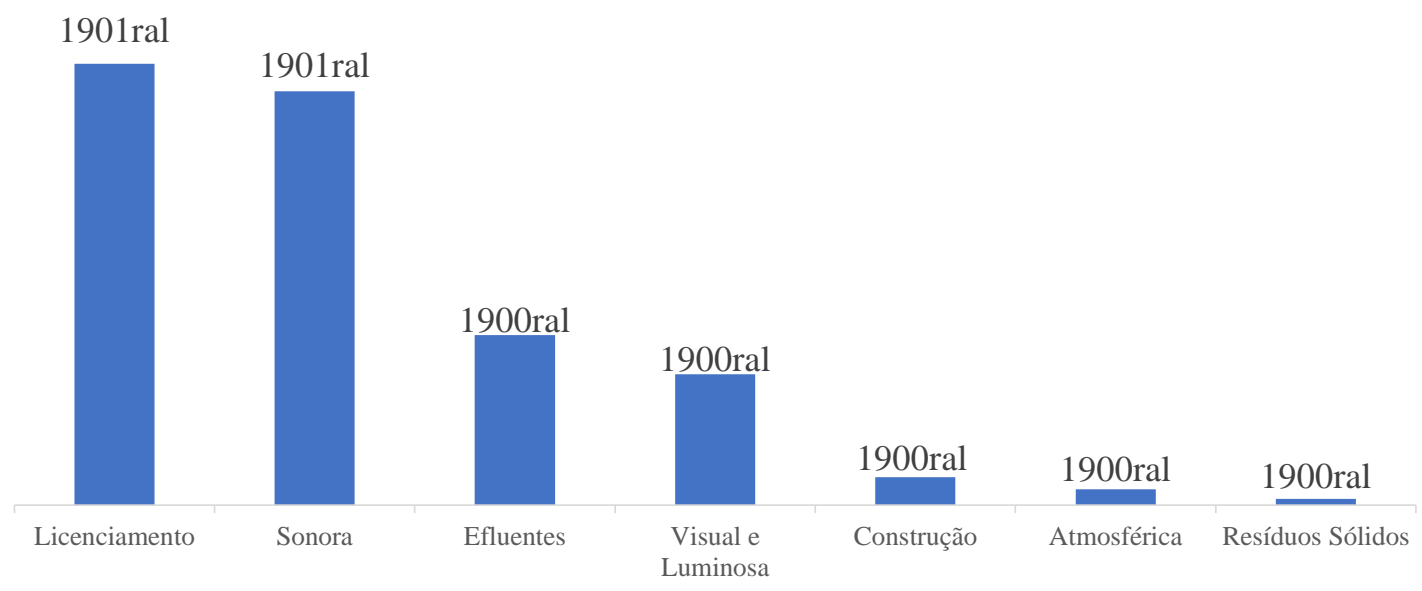

Fonte: Elaborado pelos autores.

Apesar da amostra contemplar 555 autos de infração por poluição sonora, apenas 321 tiveram os decibéis divulgados e, destes que evidenciaram esta informação, observou-se que a maior parte $(68,22 \%)$ se enquadra na faixa de 65 a $85 \mathrm{~dB}$, havendo $26,48 \%$ deles que atingiram mais de $85 \mathrm{~dB}$ (Gráfico 2), o que indica que a maior parte destas autuações sonoras são nocivas a humanos. Entretanto, 234 (29,59\%) autos não tiveram o valor dos decibéis da poluição divulgados devido ao infrator ter efetuado o desligamento do aparelho de som antes dos fiscais medirem os níveis de pressão sonora.

Gráfico 2. Quantidade de autos distribuídos em faixas de decibéis

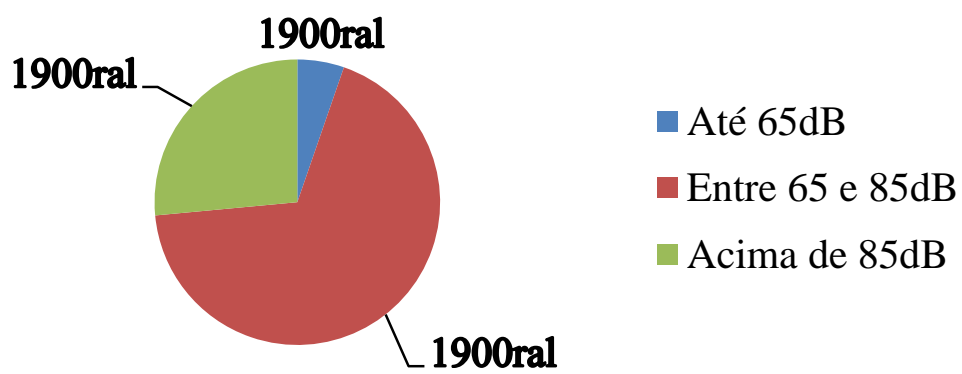

Fonte: Elaborado pelos autores.

Nas informações coletadas da amostra, 72,61\% (403 autos) das infrações foram praticadas por pessoas físicas (PF) e 27,39\% (152 autos) por pessoas jurídicas; quanto à gravidade do 
dano, 38,38\% (213 autos) apresentaram, enquanto que 61,62\% (342 autos) não apresentaram gravidade; em se tratando da reincidência, um total de $80 \%$ (444 autos) dos infratores não eram reincidentes e 20\% (111 autos) eram reincidentes (Gráfico 3).

Gráfico 3. Perfil dos poluidores

口PF $\square$ Sem potencial poluidor $\square$ Não reincidente
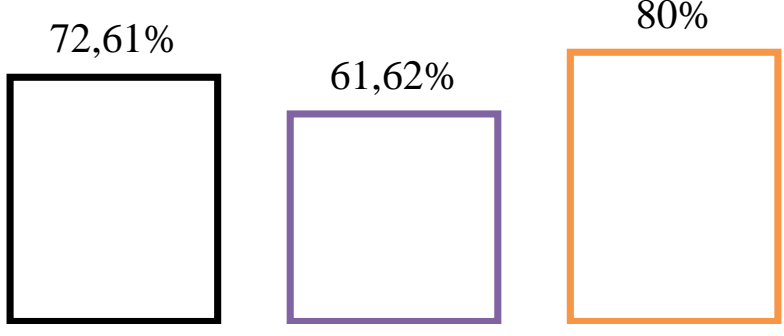

Fonte: Elaborado pelos autores.

Nos autos analisados, a maior causa de poluição sonora na cidade de Fortaleza/CE é a utilização indevida de carro de som. Esse tipo de equipamento sonoro é utilizado principalmente para entretenimento e, geralmente, ocorre em via pública.

Com relação à variável gravidade do dano percebe-se que a maioria $(54,6 \%)$ dos infratores está enquadrado nela, ou seja, grande parte das infrações cometidas eram graves. No tocante à reincidência, nota-se que poucos infratores são reincidentes. Todavia, em relação à capacidade econômica dos infratores, percebe-se uma amostra heterogênea, onde, alguns infratores possuem altos rendimentos e outros não, promovendo uma alta variabilidade dos dados. Isso se evidencia com o desvio padrão desta variável, cujo valor foi de 1.437,77 e consiste em uma medida de dispersão indicando se os elementos estão próximos da média ou não. Logo, quanto mais distante da média esses elementos estão, maior o desvio padrão, indicando uma maior dispersão dos dados. Ressalta-se que a amostra considera PF e PJ, sendo esse segundo tipo o que possui, geralmente, a capacidade econômica maior que as pessoas naturais, o que poderia explicar parte da variabilidade desta variável. Uma menor parcela da 
amostra $(31,5 \%)$ eram reincidentes neste tipo de infração. Os resultados apresentam média, desvio padrão e número de observações para cada variável (Tabela 1).

Tabela 1. Relação entre as variáveis independentes e medidas de posição e dispersão

\begin{tabular}{cccc}
\hline Variáveis & Média & Desvio Padrão & $\mathbf{N}^{\circ}$ \\
\hline GD & 0,546 & 0,687 & 555 \\
CE & $\mathrm{R} \$ 290.539,37$ & $1.437,77$ & 555 \\
REINC & 0,315 & 0,539 & 555 \\
\hline
\end{tabular}

Fonte: Elaborado pelos autores.

Em seguida aplicou-se o modelo de regressão linear múltipla, no intuito de verificar quais variáveis poderiam ser influenciadoras do valor das multas aplicadas nas autuações. Os resultados apresentaram $\mathrm{R}^{2}$ de 0,0641 de capacidade do modelo, isto é, as variáveis independentes conseguem explicar apenas $6,41 \%$ da variável dependente, apontando que outros fatores não observados podem estar influenciando o valor que os fiscais estão aplicando nas multas.

Observa-se que a Gravidade do Dano (GD) não apresentou influência estatisticamente significativa $(\mathrm{p}$-value $=0,21)$ sobre o valor das multas aplicadas por poluição sonora no município de Fortaleza/CE (Tabela 2). Contudo, as demais variáveis (capacidade econômica e reincidência), possuem significância ao nível de $1 \%$, ou seja, pode-se identificar que as duas são possíveis influenciadoras do valor calculado para a multa por poluição sonora, tendo ambas um relacionamento positivo, quanto maior a capacidade econômica e quando o infrator é reincidente, maior é o valor da multa aplicada

Tabela 2. Variáveis independentes e resultados

\begin{tabular}{|c|c|c|}
\hline Variáveis & 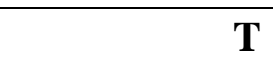 & p-value \\
\hline $\mathrm{CE}$ & 3,7 & 0,000 \\
\hline GD & $-1,26$ & 0,210 \\
\hline REIN & 4,39 & 0,000 \\
\hline
\end{tabular}

Fonte: Elaborada pelos autores. 


\section{Discussão}

A temática de se atribuir um valor aos danos ambientais é permeada por um extenso debate, afinal como o Poder Público poderia estabelecer um valor a título de punibilidade e compensação pelo impacto socioambiental causado pelo infrator. A este respeito Silva \& Corrêa (2015) discorrem que há um elevado grau de subjetivismo embutido na valoração de danos ambientais indiretos, fazendo com que distorça pelo pragmatismo da materialidade pericial. Em seu estudo, percebeu-se a arbitrariedade e o subjetivismo no ato de aplicar uma multa nos prejuízos causados ao meio ambiente.

O trabalho conseguiu alcançar seu objetivo ao avaliar os fatores que influenciam os autos de infração por poluição sonora, considerando uma amostra de 555 autos na cidade de Fortaleza. Os achados da pesquisa indicam que das três variáveis do modelo, as únicas que apresentaram influência sobre o valor das multas por poluição sonora foram a capacidade econômica e a reincidência, apontando assim, que a variável gravidade do dano pode não ser considerada no momento que o agente fiscalizador define o valor da penalidade. Este comportamento estaria parcialmente em desacordo com a legislação (art. $4^{\circ}$, do Decreto $\mathrm{n}^{\circ}$ 6.514, de 22 de julho de 2008, que expressa que esses três elementos basilares devem ser indicados no ato da infração), propiciando maior subjetivismo e insegurança na aplicação e cumprimento da penalidade, conforme Silva \& Corrêa (2015).

Logo, há indício de certo grau de arbitrariedade no ato de aplicar multas aos infratores de poluição sonora. Essa arbitrariedade também foi encontrada por Silva \& Corrêa (2015) que elencaram que o valor de um dano ambiental é função do método utilizado para precificá-lo, pois, para eles, há subjetivismo embutido na valoração de danos indiretos. O valor das multas não é influenciado, unicamente, pela gravidade do dano, e sim, pelo método utilizado.

Analisando os autos de infração de 2017 da SEUMA, o valor das multas não é baseado por métodos de valoração de dano ambiental, mas por duas das três variáveis presentes na legislação, que é compulsória. A não influência da variável gravidade do dano no valor das multas fornece o entendimento de que não importa a gravidade do dano e o impacto causado, a multa aplicada será a mesma, havendo subjetivismo. 
Os resultados do presente estudo não concordam com Cohen \& Castillo (2017), quando constataram que as principais causas de poluição nas cidades foram transporte, construção e crescimento populacional acelerado, visto que apenas dois autos tiveram como causa a construção. Nesta pesquisa, identificou-se que a maior parte dos infratores são pessoas físicas $(72,61 \%)$, tendo causa atribuída geralmente a utilização de carro de som.

Além disso, constatou-se que quando os decibéis são divulgados, em sua maioria, são em níveis nocivos à saúde, em seu trabalho Sanchez (2015) apontam que até 65 dB não prejudicam a saúde auditiva, entre $65 \mathrm{~dB}$ e $85 \mathrm{~dB}$ começa a se tornar perigoso ao ser humano e acima de $85 \mathrm{~dB}$ são considerados potencialmente perigosos. Os níveis sonoros identificados na pesquisa podem acarretar diversos problemas às pessoas, desde o incômodo do sossego alheio até traumas auditivos permanentes, sobretudo nos casos de longa exposição.

O trabalho possui limitações como o recorte temporal e espacial estarem restritos a uma única realidade, ano de 2017 e à cidade de Fortaleza (CE), respectivamente, além das autuações analisadas se referirem às fiscalizações do Poder Público Municipal. Mesmo com a adoção de práticas metodológicas que têm o intuito de minimizar tais deficiências, a pesquisa esbarra na dificuldade do levantamento de dados, uma vez que estes não estão tabulados de forma organizada em sua fonte e há restrito acesso às informações, visto que estas não são liberadas para público, sendo o acesso completo liberado mediante termo de cooperação entre o Poder Público e pesquisadores, limitando a quantidade de cidades e horizonte temporal acessível. Apesar disto, o estudo contribui com a área ao apresentar uma visão sobre a prática da atribuição de valor à pena por poluição sonora e apresentar possíveis fatores que influenciam este valor. Pesquisas posteriores podem aprofundar a temática ao considerar outras cidades que possuam órgãos fiscalizadores, bem como apresentar uma análise temporal mais longa ou mesmo utilizar-se de métodos estatísticos para comparar os determinantes da multa por infração sonora e de outros tipos.

\section{Agradecimentos}

À Universidade Federal do Ceará, no âmbito do Programa Institucional de Bolsas de Iniciação Científica (PIBIC), pelo apoio financeiro nos estudos desenvolvidos nesta pesquisa. 
À Prefeitura de Fortaleza, sobretudo à Secretaria Municipal de Urbanismo e Meio Ambiente (SEUMA), pelo apoio na disponibilidade dos dados, bem como acesso ao sistema de informações dos autos de infração, através do Termo de Cooperação Técnica No 01/2017.

\section{Referências}

Brasil. Decreto n. 6.514, de 22 de julho de 2008. Brasília/DF, 2008.

Brasil. Lei n. 9.605, de 12 fevereiro de 1998. Brasília/DF, 1998.

Cohen, M. A. \& Castillo, O. S.. (2017). Ruido en la ciudad. Contaminación auditiva y ciudad caminable. Estudios demográficos y urbanos, v. $32, \quad$ n. 1, p. 65-96. http://doi.org/10.24201/edu.v32i1.1613.

Fortaleza. Lei n. 4.822, de 27 de dez. de 1976. Fortaleza: Prefeitura Municipal, 1976.

Fortaleza. Lei n. 8.097, de 02 de dez. de 1997. Fortaleza: Prefeitura Municipal, 1997.

Fortaleza. Lei $n^{\circ}$ 10.644, de 22 de novembro de 2017. Fortaleza: Prefeitura Municipal, 2017.

IBGE - Instituto Brasileiro de Geografia e Estatística. (2017). Renda per capita do estado do Ceará. Disponível em: https://www.ibge.gov.br/cidades-e-estados/ce.html. Acessado em 15 de maio de 2020.

Sanchez, L. E.. (2006). Avaliação de impacto ambiental: conceitos e métodos. $2^{\mathrm{a}}$ ed. São Paulo: Oficina de textos, 529p.

Silva, T. B. B. d. \& Corrêa, R. S. (2015). Comparação entre métodos de valoração de danos ambientais para fins periciais. Revista Brasileira de Criminalística, v. 4, n. 3, p. 7-14. https://doi.org/10.15260/rbc.v4i3.101. 